\title{
La revancha patriarcal. Cruzada moral y violencia sexual en Mendoza (1972-1979)
}

\author{
The patriarchal revenge. Moral crusade and sexual \\ violence in Mendoza (1972-1979)
}

\author{
Alejandra Ciriza \\ Consejo Nacional de Investigaciones Científicas y Técnicas \\ Universidad Nacional de Cuyo \\ (Argentina) \\ aciriza@mendoza-conicet.gob.ar \\ Laura Rodríguez Agüero \\ Universidad Nacional de Cuyo \\ (Argentina) \\ 1rodriguezaguero@gmail.com
}

\section{Resumen}

La incorporación de las mujeres al activismo político en los años '60 y '70 introdujo perturbaciones en el orden de las relaciones inter-genéricas que los militares se propusieron restaurar. Ya en los años previos al golpe de Estado se fue actuando en esa dirección. En el caso de Mendoza, bajo la idea de que era necesario preservar el orden moral, las fuerzas de seguridad y grupos de la derecha nacionalista local reaccionaron en forma virulenta por un lado, frente a instancias asamblearias protagonizadas por maestras en los denominados "Seminarios Educativos", y por otro, contra mujeres en situación de prostitución, las cuales fueron brutalmente perseguidas por comandos parapoliciales.

En este trabajo, nos proponemos analizar rupturas y continuidades en el accionar represivo, así como dar cuenta de la cruzada "moral" impulsada por los militares, partiendo de la hipótesis de que el castigo aplicado tanto a aquellos denominados "subversivos/as" como a las mujeres en situación de prostitución, estuvo vinculado y se halla inscripto en relaciones asimétricas entre los géneros sexuales, y que la última dictadura implicó, además de una "revancha clasista", una de corte "patriarcal".

Palabras Clave: Represión - Género - Historia Reciente

1. BASUALDO, Victoria, "Complicidad patronal-miliar en la última dictadura militar. Los casos Acindar, Astarsa, Dálmine, Siderca, Ford, Ledesma y Mercedes Benz”, en Suplemento especial Revista Engranajes, Buenos Aires, 2006, No 5, FETIA. 


\begin{abstract}
The incorporation of women into political activism in the 60s and 70s introduced disruptions in gender relations order that the military then decided to restore. Already in the years before the putsch there were actions in this sense. In the case of Mendoza, under the idea that it was necessary to preserve the moral order, security forces and local nationalist groups reacted virulently. On the one hand, they reacted against the Educational Seminars organized by teachers, and on the other hand, against prostitutes, who were brutally persecuted by "parapolicial" commands.
\end{abstract}

In this paper, we analyze ruptures and continuities in the repressive action, as well as the development of the "moral" crusade led by the military. We depart from the assumption that the punishment meted out to those called "subversives" and prostitutes, was based on asymmetric relations between the genders. In this article we consider that the last dictatorship involved, along with a "class revenge," one of "patriarchal" nature.

Key Words: Repression - Gender - Recent History

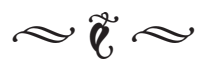

\section{Introducción}

\section{"La enemiga interna": maestras, feministas y prostitutas}

En este trabajo nos interesa indagar en la hipótesis de que el golpe de Estado de 1976 a la vez que resolvió de manera violenta la combinación de las crisis económica, política y social arrastradas por décadas, implicó un esfuerzo sistemático por restaurar los roles "naturales" de género. Así como las respuestas articuladas de la clase dominante y el Estado implicaron lo que Victoria Basualdo denomina una "revancha clasista" que logró poner fin a la situación de crisis de hegemonía a través de la puesta en marcha del terrorismo de
Estado, nuestra hipótesis es que la dictadura también implicó una "revancha patriarcal" y un proceso de "restauración moral" que buscaba poner freno a la "subversión" de las relaciones inter-genéricas y de los valores occidentales y cristianos, los cuales habían sido puestos en riesgo por la "infiltración comunista" y las "ideologías extranjerizantes" sobre el papel de las mujeres. Vale la pena señalar que, si bien los estudios sobre la represión en la historia argentina reciente han tenido un significativo desarrollo, aquellos que han abordado este proceso desde la perspectiva de género son escasos. Este trabajo aporta a este espacio de discusión, desde un análisis de dichos procesos a escala local. ${ }^{2}$

2.Algunos trabajos que han abordado esta temática son: D’ANTONIO, Débora, "Los presos políticos del penal 
En Mendoza, tanto en los años previos como posteriores al golpe de Estado de 1976, se produjeron una serie de hechos que suelen presentarse ante una primera lectura como aislados, pero que pueden ser leídos como parte de un proceso de restauración de la moral y la política patriarcales. En este trabajo intentaremos abordar este costado menos explorado del proceso represivo, así como la participación de ciertos actores civiles a los cuales se ha prestado poca atención. Así como en lo público la dictadura se presentaba como gendarme y garante de la familia y llamaba a recuperar los roles de género tradicionales, esa prédica tuvo su contracara en los centros clandestinos, en el accionar parapolicial y en las cárceles de la dictadura, donde se llevó a cabo una política de represión sexualizada sobre

de Rawson: un tratamiento para la desubjetivación. Argentina (1970 1980), en Anos 90, Dossiê Ditaduras de Segurança Nacional no Cone Sul, Porto Alegre, 2012, V. XIX, No. 35, pp. 141-168; BACCI, Claudia, CAPURRO, María, OBERTI, Alejandra y SKURA, Susana, "Entre lo público y lo privado: los testimonios sobre la violencia contra las mujeres en el terrorismo de Estado en Argentina", en Clepsidra, Revista Interdisciplinaria de Estudios sobre la Memoria, Revista del Núcleo de Estudios sobre Memoria (IDES), Buenos Aires, 2014, Año 1, № 1. AUCÍA, Analía, BARRERA, Florencia, BERTERAME, Celina, CHIAROTTI, Susana, PAOLINI, Alejandra y ZURUTUZA, Cristina, Grietas del silencio. Una investigación sobre la violencia sexual en el marco del terrorismo de Estado, CLADEM, Insgenar, Buenos Aires, 2011; CIRIZA, Alejandra, "Sobre las violaciones cometidas en los centros clandestinos de detención como delitos de lesa humanidad", en Sin Permiso. Disponible en:

$<$ http://www.sinpermiso.info/textos/index.

php?id=3807>, [Consulta: 7 de setiembre de 2014]; BALARDINI, Lorena, OBERLIN, Ana y SOBREDO, Laura, "Violencia de género y abusos sexuales en centros clandestinos de detención. Un aporte a la comprensión de la experiencia Argentina”, en CELS, Hacer justicia. Nuevos debates sobre el juzgamiento de crimenes de lesa humanidad en la Argentina, Siglo XXI, Buenos Aires, 2011. varones y mujeres orientada al exterminio de los y las enemigas políticas. Las mujeres fueron desmaternalizadas, violadas de manera sistemática, estigmatizadas como "putas", mientras los varones fueron desmasculinizados, violados, vejados de diversas maneras en su virilidad, una "contracara de lo que el régimen anunciaba públicamente". ${ }^{3}$

Este trabajo toma algunos delos conflictos que tuvieron como escenario a Mendoza en el lapso que va desde el "Mendozazo" $(1972)^{4}$, hasta los primeros años de la dictadura, considerando que en 1979 la visita de la Comisión Interamericana de Derechos Humanos forzó al régimen a atenuar parcialmente sus prácticas represivas. En primer lugar se abordarán dos experiencias protagonizadas por mujeres que generaron la reacción de la derecha local: los "Seminarios Educativos" donde miles de maestras elaboraron un progresivo proyecto de ley provincial de educación; y una publicación encarada por un grupo de feministas en los tempranos '70, resultado

3. D'ANTONIO, Débora, "Los presos políticos...", Op. Cit., p. 23.

4. El 4 de abril de 1972, en un clima de descontento y repudio generalizado hacia las políticas de la Revolución Argentina, se produjo un aumento del $300 \%$ en las tarifas eléctricas. Esto llevó a la formación de la Coordinadora "No pague la luz", que dispuso concentraciones, apagones y asambleas. Entretanto la Confederación General del Trabajo (CGT) regional convocó a un paro con movilización para el 4 de abril. Ese día se realizó una multitudinaria movilización que tomó las calles. La respuesta por parte del gobierno no se hizo esperar, y ya en la mañana del 4 fueron brutalmente reprimidos/as trabajadores/as de la educación frente a su sede gremial y trabajadores de la CGT que estaban concentrados frente al local. Luego el enfrentamiento se trasladó a Casa de Gobierno. Ese día el saldo fue de un muerto y cientos de heridos y detenidos. El conflicto se extendió por varios días y provocó la renuncia del interventor Gabrielli y la suspensión de los aumentos de tarifas. 
de conferencias y seminarios realizados en la ciudad de Mendoza. En segundo lugar, se describirá la persecución sufrida por mujeres en situación de prostitución en los años previos al golpe de marzo del '76, apuntando a analizar continuidades -y rupturas- en las prácticas represivas sexuadas hacia mujeres militantes durante la dictadura. Todo ello bajo la idea de que la cruzada encarada por las Fuerzas Armadas (FFAA) fue política y económica pero también moral y religiosa, hecho que se ve plasmado tanto en la actuación de comandos paraestatales que perseguían a mujeres en situación de prostitución, como en el particular trato que recibieron las mujeres, y algunos varones, en los Centros Clandestinos de Detención (CCD).

Las fuentes utilizadas en esta investigación son: diarios, publicaciones de la época, entrevistas y declaraciones testimoniales obtenidas de los juicios por crímenes de lesa humanidad. ${ }^{5}$

\section{Maestras y feministas: salirse del orden establecido}

En la Mendoza de los ‘60 y '70 las maestras tuvieron un destacado protagonismo en las jornadas del "Mendozazo". Su lucha, que en un comienzo fue reivindicativa, avanzó rápidamente hacia una batalla por la definición del sentido de la educación.

Los "Seminarios Educativos", realizados durante septiembre y octubre de 1973, fueron instancias asamblearias en las que docentes de toda la provincia discutieron el futuro proyecto

5. Obtenidas en <https://juiciosmendoza.wordpress. com> de ley de educación a partir de una serie de pautas elaboradas por el gobierno y el gremio. Según los documentos, estas pautas partían de la idea de que era necesaria una transformación de la educación pues "la clase dominante organiza el proceso educativo teniendo fundamentalmente en cuenta sus intereses de clase". ${ }^{6}$ La sociedad, desde la perspectiva de las y los docentes, debía encaminarse hacia un nuevo orden social basado en la propiedad social y en la colaboración fraternal. ${ }^{7}$ Parte de esa transformación era la propuesta de creación de guarderías infantiles, pues los/as docentes entendían que las madres trabajadoras debían contar con lugares que aseguraran la atención a los/as pequeños/as desde los 45 días hasta los 4 años.

Integrantes de grupos nacionalistas católicos, encabezados por Dennis Cardozo Biritos (quien fue durante la dictadura militar Rector de la Universidad Nacional de San Luis) y Abelardo Pithod (referente del Opus Dei y seguidor de Carlos Alberto Sacheri, quien afirmaba que la educación estaba en crisis porque se había derrumbado el marco greco-latino e hispánico y se declaraba tomista y admirador de Guido Soaje Ramos) interpretaron la propuesta como un ataque a "la" familia (que en su concepción es y debe ser patriarcal y heteronormativa). En esa dirección, organizaron una encarnizada oposición a los "Seminarios Educativos", que se materializó en el boicot de las cientos de asambleas realizadas en toda la provincia, en marchas de silencio y antorchas, entrevistas con funcionarios provinciales y nacionales $\mathrm{y}$ solicitadas en los diarios.

6. Claves, Mendoza, 5/10/1973, p. 4.

7. Ibídem. 
Los enfrentamientos entre docentes de escuelas públicas y confesionales comenzaron a fines de agosto de 1973, cuando estos últimos y la Liga de Madres de Familia reclamaron tener voz y voto en las discusiones. El gobierno provincial atendió el reclamo. Aun así, a comienzos de septiembre la Federación de Padres de Alumnos de Escuelas Privadas y Oficiales se presentó en el diario Mendoza para denunciar las “... medidas gubernamentales... conducentes a establecer el monopolio estatal de la educación... que provienen de la infiltración marxista que hay en el gobierno provincial". ${ }^{8}$ Ambos grupos, que habían sido creados y dirigidos por los académicos mencionados, manifestaron su preocupación por "la entrega de niños a las guarderías para facilitar la emancipación de la mujer" y por el uso del término "propiedad social" por estar posiblemente vinculado a "ideologías extranjeras". También el Sindicato Unido de Trabajadores de la Educación (SUTE) fue acusado de sostener "tesitura marxista y condiciona[r] el trabajo de los seminarios". ${ }^{10}$

E119 de septiembre convocaron a una Marcha del Silencio para denunciar la "infiltración del marxismo internacionalista” en la educación $\mathrm{y}$ entregaron un petitorio al gobernador en el que, entre otras cosas, reclamaban que se opusiera a "todo intento de infiltración marxista en el Estado, especialmente en la educación teniendo en cuenta que el pueblo argentino, en un 98\% rechaza esta aberrante y deshumanizada filosofía". ${ }^{11} \mathrm{Al}$ día siguiente, una nueva asamblea convocada por el SUTE,

8. Mendoza, Mendoza, 19/9/1973, p. 5.

9. Claves, Mendoza, Op. Cit. p. 4.

10. Ibídem.

11. Mendoza, Mendoza, 20/9/1973, p. 7. que se realizó en el teatro Independencia, terminó con el retiro de los padres y docentes de escuelas privadas que marcharon por las calles de la ciudad y manifestaron haberse sentidos agraviados en la asamblea. En una entrevista realizada en 2012 a Josefina Orozco, maestra y dirigente sindical, señala al respecto:

En una de las asambleas realizada en el teatro Independencia, la platea estaba copada por monjas encabezadas por Cardozo Biritos... [que] da un discurso que termina diciendo "y si quieren tirar tiren", $y$ se abre el saco. Se ve que esa era la señal para que se fueran y dejaran despejada la platea. Pero el acto siguió. ${ }^{12}$

Las maestras lograron, en esa oportunidad, que el gobernador Martínez Baca permaneciera en el acto. Pero la ofensiva católica no cesó. Cardozo Biritos, declaraba a Claves que "Todo padre que vea amenazado el derecho de educar a sus hijos se dejaría matar antes de verlos opuestos a sus progenitores y a las tradiciones de la patria, por un lavado de cerebro del marxismo internacional". ${ }^{13}$

Frente al creciente conflicto generado por los Seminarios, la comisión Justicia y Paz del arzobispado emitió una declaración en la que señalaba que:

las pautas educativas son inaceptables para la conciencia cristiana de nuestro pueblo... propician una enseñanza laica, omitiendo la formación religiosa de los niños... presentan a la cultura y los sistemas educativos como simples productos de la estructura económica... niegan el derecho

12. Entrevista realizada por Laura Rodriguez Agüero y Alejandro Sanfurgo a Josefina Orozco, militante y dirigente docente, Mendoza, noviembre de 2012.

13. Claves, Mendoza, Op. Cit., p. 6. 
de los padres a educar a sus hijos... procuran desligar al niño en edad preescolar de la madre... ${ }^{14}$

En una entrevista realizada en 2013, Judith Carunchio, una de las cinco redactoras de las Pautas, señala:

A las putas se las acusó de marxistas, de atacar a la escuela tradicional y nuestros planteos se han implementado en los últimos años sin que nadie haya dejado de ser argentino ni escapase a Rusia. Nos criticaban las guarderías porque no le dejábamos a la familia el rol de educar, nuestro planteo libertario los asustó... queríamos liberar a la mujer y éramos el demonio, éramos una ruptura inaceptable. ${ }^{15}$

Efectivamente, determinados puntos de las Pautas, principalmente la creación de guarderías infantiles, constituyeron "una ruptura inaceptable". Los sectores conservadores y ligados a la Iglesia Católica organizaron "Seminarios Paralelos". Además enviaron un telegrama al presidente de la Nación señalando que "Ante evidente ideología marxista premura impuesta e información engañosa en seminarios educativos de Mendoza, solicitamos postergación de los mismos. Maestros en seminarios paralelos". ${ }^{16}$ Alegaban actuar en sintonía con el gobierno nacional, pues Perón a través del Documento Reservado llamaba a los peronistas "a definirse públicamente en esta situación de guerra contra los grupos marxistas" y a "participar activamente en las acciones que se planifiquen

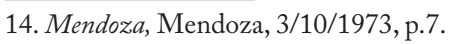

15. Entrevista realizada por Laura Rodriguez Agüero a Judith Carunchio, militante y dirigente docente, Mendoza, marzo de 2013.

16. Mendoza, Mendoza, 4/10/1973, p. 3.

54 para llevar adelante esta lucha". ${ }^{17}$

Frente al revuelo, la comisión redactora respondió señalando que las pautas no implicaban condicionamiento para el debate, sino que se trataba de un documento de consulta "propio de un magisterio que... no puede resignar el derecho de... señalar los graves problemas de la cultura, de la educación, sobre la base de una objetiva interpretación de la realidad". ${ }^{18}$ También defendían la idea de que la educación "no puede ser examinada al margen de las relaciones de producción y las fuerzas productivas" y sostenían no haber hablado de una supuesta liberación de la mujer "sino específicamente de la liberación de la mujer". ${ }^{19}$

E1 24 de octubre comenzaron las sesiones de trabajo del Congreso, durante las cuales, sobre la base de lo debatido en las escuelas, se elaboraría un anteproyecto de ley para presentar al Ejecutivo, quien sería responsable de su redacción definitiva. En caso de ser aprobado por los/as docentes, el mismo pasaría a la Legislatura.

Pero el debate se detuvo allí. El avance de la derecha a nivel provincial y nacional frenó el proyecto producido a partir de los Seminarios. Pese a las presiones del gremio, el cambio en la correlación de fuerzas se tradujo, entre otras cosas, en la designación de nuevas autoridades en materia educativa. De Francisco Reig, ministro ligado a la izquierda peronista, se pasó a personajes del nacionalismo católico como el historiador Jorge Scalvini Ochoa, quien al asumir en julio del 75 anunció: "debemos

17. Ibídem.

18. Mendoza, Mendoza, 4/10/1973, p. 3.

19. Mendoza, Mendoza, 5/10/1973, p. 3 . 
llevar adelante la reconstrucción del hombre argentino, respetando la verticalidad de la cruz, de nuestra tradición hispana y cristiana" ${ }^{20}$ Scalvini Ochoa fue reemplazado en noviembre de ese año por Rodolfo Mendoza, uno de los referentes más importantes de la ultraderecha católica, fundador de la Fraternidad Apostólica Santo Tomas de Aquino (FASTA). En este escenario, las posibilidades de que las conclusiones resultantes de los Seminarios llegaran a la Legislatura, se esfumaron. E1 tema no volvió a ser mencionado.

No sólo las maestras sindicalizadas y convencidas de la importancia de transformar la educación eran percibidas como una amenaza contra la "familia". Entre 1969 y 1972 existió en la provincia el Centro de investigaciones de la Mujer (CIM), vinculado a grupos ecumenistas y de católicos tercermundistas que buscaban abrir horizontes hacia la teología de la liberación. ${ }^{21}$ Como resultado de las conferencias y Seminarios realizados en la ciudad de Mendoza en el Instituto de Acción Social y Familiar, se publicó Opresión $y$ marginalidad de la mujer en el orden social machista. $^{22}$

\section{Ibídem.}

21.YAÑEZ, Anabella, "Diagnóstico de la situación de la mujer en el momento actual”, en ANDER EGG, Ezequiel, ZAMBONI, Norma, GISSI, Jorge, DUSSEL, Enrique, Opresión y marginalidad de la mujer en el orden social machista, Humanitas, Buenos Aires, 1972, p. 90.

22.ANDER EGG Ezequiel, ZAMBONI, Norma, GISSI, Jorge, DUSSEL, Enrique, Opresión y marginalidad..., Op. Cit. El libro incluye trabajos de Norma Zamboni y Ezequiel Ander Egg, un testimonio de Anabella Yáñez, un conocido folleto del psicólogo chileno Jorge Gissi, "Mitología de la femineidad", que fuera también publicado por Nueva Mujer, un grupo editorial de feministas porteñas, y un artículo de Enrique Dussel. Merecen especial mención los textos de Zamboni y Ander Egg y el escrito en primera persona
El libro parte de la idea de que ha llegado la hora de las mujeres, el momento de entrar en el mundo que los hombres concibieron y edificaron a su imagen y semejanza para transformarlo cambiando por entero el rostro de la civilización humana. Parafraseando a Stuart Mill sostenían que las mujeres habían sido entregadas como esclavas a los hombres desde los primeros días de la sociedad humana y que su emancipación sería la medida de la emancipación humana. ${ }^{23}$

Si el escrito de Ander Eggy Zamboni apunta a proporcionar herramientas teóricas, el de Yañez, que también recurre a las herramientas conceptuales disponibles: las reflexiones y textos de Castilla del Pino y Simone de Beauvoir, están tamizados por el trabajo colectivo de pensar acerca de las marcas de "alienación" de las mujeres en sus vidas cotidianas. Las mujeres son la "encarnación trágica de un destino: no ser ella[s] misma[s]". ${ }^{24}$ Alienadas debido a una cultura y una educación que las subordina al hombre, al amor romántico, a un destino inevitable de maternidades y corveas domésticas, las mujeres rechazan sordamente su condición de oprimidas y el destino que, según se dice, la biología les ha fijado.

Para Yáñez, sólo una ardua reflexión y el trabajo individual y colectivo contribuirán a la "emancipación" de las mujeres, que no es un asunto individual, sino un deber moral que ha de transformar el futuro de la humanidad, pues su situación es tal que la modificación de su

de Yáñez, titulado "Diagnóstico de la situación de la mujer en el momento actual" pues la autora pone en palabras el resultado de una experiencia colectiva de reflexión realizada durante esos años.

23. Ídem, p. 85.

24. YAÑEZ, Anabella, "Diagnóstico de la situación...”, Op. Cit., p. 90. 
suerte ha de modificar el entero orden social. Sobre esa base Yáñez despliega una serie de ideas acerca de la libertad y el deber moral de encarar una lucha que abrirá las puertas a la humanidad futura, que será posible por la llegada de una mujer nueva. ${ }^{25} \mathrm{Y}$ dice: "Sí, hermanas, temamos ahora que aún estamos a tiempo de poseer futuro. Aún podemos ser nosotras mismas... es tan duro todo esto que comprendo el rechazo... Comprendo cómo S. de Beauvoir escribió la mujer rota sin hacer más que retratar la vida en vez de argumentar" ${ }^{26} \mathrm{Y}$ continúa:

Esas mujeres del tiempo que se anuncia, esas que deberán construir colectivamente un proyecto de liberación humana serán solidarias entre sí pues no serán los varones, sino ellas mismas el centro de sus vidas y proyectos. De las dificultades del camino hacia la liberación, pues hay mujeres que desconocen su subordinación; mujeres que la conocen, pero temen enfrentarla; mujeres que luchan por el cambio, pero se destruyen en el esfuerzo aislado, [surge]... la imperiosa necesidad de una praxis colectiva. ${ }^{27}$

Durante estos años de "toma del cielo por asalto" la articulación de redes de hombres y mujeres que bregaban por una transformación del orden social capitalista y patriarcal muestra una serie de anudamientos: la lucha de las maestras estaba vinculada a quienes formaron parte de la experiencia feminista protagonizada por las /os integrantes del Instituto de Acción Social y Familiar, que se hallaba vinculado al movimiento ecuménico y al desarrollo del movimiento de curas tercermundistas. Ezequiel Ander Egg fue el encargado de

25. Ídem, p. 111.

26. Ídem, p. 96.

27. Ídem, p. 119.

56 la redacción de las pautas educativas que tanto revuelo causaron. A su vez todos/as ellos/as estuvieron vinculados a las acciones de solidaridad con el pueblo chileno tras el golpe militar del 11 de septiembre de 1973 contra el gobierno de Salvador Allende. En el Instituto por la Liberación y Promoción Humana (ILPH), que se formó por entonces, confluyeron la educadora popular Norma Zamboni, el sociólogo Ander Egg, los académicos y teólogos ligados al movimiento de curas tercermundistas Oscar Bracelis, Rubén Dri, Mauricio López, los sacerdotes católicos Pérez y Contreras, el filósofo Enrique Dussel y también una joven pastora holandesa, Alieda Verhoeven, compañera de Safina Newbery en los complejos rumbos de la teología feminista.

Estas experiencias: gremiales, religiosas, feministas, cuestionaban puntos neurálgicos del status quo en torno a la división sexual del trabajo, la maternidad, el rol que cabía a las docentes, las relaciones entre mundo público y privado, la moral sexual, la idea misma de dios. De allí que fueran percibidas como amenazantes por los sectores civiles y militares que tomaron el poder en marzo de 1976.

\section{A la caza de las brujas}

Toda la brujería proviene del apetito carnal que en las mujeres es insaciable... Por lo cual, para satisfacer sus apetitos, se unen inclusive a los demonios. Muchas más razones deberían presentarse, pero para el entendimiento está claro que no es de extrañar que existan más mujeres que hombres infectadas por la herejía de la brujería. ${ }^{28}$

El intento de "restaurar las relaciones

28. SPRENGER, Jacobus y KRAMER, Heinrich, 
naturales de género", se hizo visible en la lucha contra los Seminarios, pero la ofensiva no quedó ahí. La puesta en marcha de lo que denominamos la "revancha patriarcal" en la provincia tuvo un temprano y significativo desarrollo, por un lado debido a la presencia del jefe de policía Julio César Santuccione, conocido públicamente como un "restaurador moral" y acérrimo defensor de la "sociedad occidental y cristiana", ${ }^{29}$ y, por otro lado, debido a la existencia de una fuerte tradición de nacionalismo de derecha. ${ }^{30}$

Mendoza contaba con un robusto movimiento integrista ${ }^{31}$, que tuvo una activa

Malleus Maleficarum (El martillo de las brujas), Reeditar, España, 2006, p. 54.

29. Santuccione se desempeñó como Jefe de Policía de la provincia de Mendoza desde el 29 de octubre de 1974 hasta el 20 de diciembre de 1976. Estuvo procesado por el secuestro y desaparición de por lo menos 20 personas, y por el funcionamiento de Centros Clandestinos de Detención.

30. Algunas de las características del "nacionalismo de derecha" son: el antiliberalismo, antiizquierdismo, corporativismo, reivindicación del catolicismo y antisemitismo. Además, la consideración de la Nación como "un bloque culturalmente monolítico, cuya preservación requería una sociedad jerárquicamente ordenada" y una visión conspirativa de la historia que llevó a una constante denuncia de complot y el llamado "a una cruzada para la reconquista del país...". En LVOVICH, Daniel, El nacionalismo de derecha, desde sus orígenes a Tacuara, Capital Intelectual, Buenos Aires, 2006, p.12.

31. La Facultad de Filosofía y Letras de la UNCuyo tuvo desde sus orígenes una fuerte influencia del nacionalismo católico tomista integrista. Desde mediados del S. XX un grupo de historiadores nacionalistas y antiperonistas (Enrique Zuleta Álvarez, Jorge Comadrán, Edberto Acevedo y Pedro Santos Martínez, entre otros) fueron becados para realizar sus estudios de posgrado en la Universidad de Sevilla y La Rábida. Señala Celina Fares que allí se encontraron con el proyecto cultural franquista como una alternativa a un mundo bipolar. "El mito de la hispanidad calaría intervención política tanto desde la Facultad de Filosofía y Letras como desde la iglesia de Santo Domingo. Diversos hechos violentos protagonizados por patotas en las que confluían miembros de las fuerzas de seguridad y del nacionalismo de derecha, dan cuenta de ello. No es difícil inferir que de sus filas salieron quienes perseguían a mujeres en situación de prostitución y que incluso se contaron entre los responsables de la colocación de bombas a miembros del movimiento ecuménico que habían incidido en la elaboración de las Pautas educativas y se hallaban vinculados al grupo de tempranas feministas mendocinas. ${ }^{32}$

\section{Los "canes de dios"}

Guardia Restauradora Nacionalista (GRN), un grupo armado de derecha católica integrista, tuvo su expresión en Mendoza en los tempranos '60. E., ex-integrante de

hondo entre los sectores conservadores y tradicionalistas ligados al catolicismo, que veían en la pervivencia del franquismo un ejemplo de orden político, cuya autoridad y jerarquía garantizaba la defensa de la religión y la tradición frente a los embates del modernismo... El franquismo se asumiría como centinela del Occidente Cristiano, en defensa del cristianismo amenazado por el comunismo, lo que en un futuro no demasiado lejano implicaría asumir otro tipo de compromisos, que no fueron solamente intelectuales". En FARES, Celina, "Tradición y reacción en el Sesquicentenario. La escuela sevillana mendocina”, en Prismas, Bernal, 2011, V.XV, № 1, p. 93.

32. A partir de 1974 actuaron en Mendoza el Comando Anticomunista de Mendoza (CAM) y el Comando Moralizador Pío XII, organizaciones cuyos propósitos eran "defender a la población de la penetración marxista" en el primer caso, y "resguardar la moral de la población" en el segundo. Ver RODRIGUEZ AGÜERO, Laura, "Ciclo de protestas, experiencias organizativas y represión paraestatal. Mendoza, 1972-1976”, Tesis Doctoral, Universidad Nacional de La Plata, 2013. 
GNR, que hacia los '70 viró hacia la izquierda peronista, señala en una entrevista realizada en 2009 el estrecho vínculo que GRN tenía con los dominicos:

Los lugares de reunión... eran las iglesias, en los Dominicos, que no es de extrañarse porque son lo más facho que hay, los Domini canes, los perros de dios. Ellos arrancaron hace muchos años siendo inquisidores $\mathrm{y}$ siguen, no han cambiado mucho. Incluso las ceremonias de juramentación las hacían ahí, en el camarín de la virgen...33

Según el testimonio de E., el Comando Pío XII, instrumento de la revancha patriarcal, estaba formado por integrantes de los servicios de inteligencia del ejército, "gente de los dominicos y policías" y "jóvenes de la ultraderecha" ${ }^{34} \mathrm{La}$ información proporcionada por E. es consistente con el testimonio de Rolando Concatti, ex cura tercermundista:

...los grupos de derecha pertenecían a los dominicos... Tenían autonomía de la iglesia... después se hicieron lefebristas... En las ceremonias de juramentación... [de] GRN en Santo Domingo se realizaban prácticas sexuales: un [a] antiquísim[a] consistía en que el jefe pedía el juramento de fidelidad,...tomarle el miembro a la autoridad [un cura] y de rodillas jurarle fidelidad. También hacían cosas homosexuales, hay una vieja tradición de la posesión sexual no por placer sino por sometimiento y fidelidad... Este tema... hizo que las mismas autoridades dominicas los desperdigaran... ${ }^{35}$

33.Entrevista realizada por Laura Rodríguez Agüero a E., ex integrante de Guardia Restauradora Nacionalista, Mendoza, mayo de 2009.

\section{Ibídem.}

35. Entrevista realizada por Laura Rodríguez Agüero a Rolando Concatti, ex cura tercermundista, integrante
A su vez, personajes del integrismo católico de la Universidad Nacional de Cuyo (UNCuyo) como Rubén Calderón Bouchet, Edberto Oscar Acevedo, Jorge Comadrán Ruiz, Francisco Ruiz Sanchez, Dennis Cardozo Biritos, Abelardo Pithod, Rosa Zuloaga, Rodolfo Mendoza, entre otros, también tuvieron una cercana relación con los dominicos. ${ }^{36}$

E. y Concatti coinciden en señalar que el sacerdote dominico Anibal Fosbery, presidente $\mathrm{y}$ fundador de FASTA, que tuvo una cercana relación con altos jefes de la dictadura militar, ${ }^{37}$ y el profesor Alberto Falcionelli, ${ }^{38}$ que fue

del Comité Ecuménico de Acción Social (CEAS), Mendoza, septiembre de 2012.

36. Todos ellos eran académicos de la Facultad de Filosofía y Letras, que como mencionamos, tenía una fuerte impronta nacionalista de derecha e integrista, y además eran parte del Instituto de Estudios Humanísticos y Sociales.

37. Según Horacio Verbitsky, FASTA colaboró con altos jefes de la dictadura: "Tanto el ex coronel Camps como el comisario Etchecolaz que lo secundó en la jefatura policial, militaron en organizaciones integristas afines a FASTA. En 1986, cuando Etchecolatz y Camps fueron condenados por la Cámara Federal de la Capital, se produjeron una serie de atentados en el Gran Buenos Aires, incluyendo la colocación de explosivos en el jardín de la casa de uno de los jueces... Por otra parte, Fosbery apoya a la Asociación de Cecilia Pando que considera "presos políticos" a los genocidas". La sede de FASTA de Bariloche funcionó durante sus primeros años en el colegio Primo Carraro, por un convenio con la Agrupación Germano Argentina que presidía Erich Priebke. Fosbery hizo un agradecimiento público a Priebke después de su extradición, concedida en 1995 para que fuera juzgado en Italia por los crímenes de las Fosas Ardeatinas. Verbitsky, Horacio, "Lo que nos FASTAba”, en Pagina12, Buenos Aires, 1/10/2006.

38. Señala Fares que Alberto Falcionelli, "de origen corso, estuvo en la guerra en el ejército de Mussolini, militó en el movimiento maurrasiano de Action Française y fue colaboracionista del gobierno de Petain. Representante de la agencia francesa Havas, se exilió 
colaboracionista nazi e integrante del régimen de Vichy en Francia, instruían a los jóvenes de GRN y tuvieron como discípulos a varios de los profesores nombrados. $\mathrm{Al}$ respecto, Ranaletti y Pontoriero resaltan el rol de adoctrinamiento de los perpetradores llevado a cabo por sectores del nacionalismo de derecha en estos años y su "aporte" en la construcción de un Estado "contra-subversivo". Según estos autores, dicho adoctrinamiento contribuyó a que la frontera entre la "civilización y la barbarie" pudiera "ser cruzada como si se tratara de un acto de servicio, o de la salvaguarda de la "civilización occidental y cristiana". ${ }^{39}$

En los convulsionados '70, los actores mencionados confluyeron en la caracterización del "enemigo interno", y algunos de ellos se incorporaron a bandas armadas y organizaciones paramilitares como el Comando Moralizador Pío XII. Estas bandas llevaron a cabo, en el clima previo al golpe, la persecución de mujeres en situación de prostitución so pretexto de moralización y colocaron aparatos explosivos en las viviendas de personas ligadas al movimiento de curas tercermundistas y de organizaciones de

en España y llegó a Mendoza en 1947 por intermedio del cura Sepich". En FARES, Celina, "Tradición y reacción...”, Op. Cit, p. 94. Mario Ranaletti sostiene, por su parte, que Falcionelli también estaba vinculado con la Central Intelligence Agency norteamericana (CIA), dato conocido a partir de las memorias de un agente asentado en Buenos Aires desde 1958. En RANALETTI, Mario, "La guerra de Argelia y la Argentina. Influencia e inmigración francesa desde 1945”, en Anuario de Estudios Americanos, Sevilla (España), 2005, V. LXII, № 2, p. 291.

39. RANALETTI Mario y PONTORIERO, Esteban, "La normativa en materia de defensa y seguridad y la criminalización de las disidencias (1955-1976)", ponencia presentada en VJornadas de Trabajo sobre Historia Reciente, Universidad Nacional de General Sarmiento, Los Polvorines, 2010. ayuda a exiliados chilenos como el sociólogo Andrés Ander Egg y la educadora popular Norma Zamboni (22/11/1975), al ex cura tercermundista Oscar Bracelis (4/10/1975), al filósofo Enrique Dussel (2/10/1973), al lugar donde se reunía el Comité Argentino-Chileno (COMACHI) (20/09/1974) y en la iglesia evangélica metodista que sirvió de refugio de exiliados (6/09/1975), contribuyendo a la creación de un clima de terror entre los/las ciudadanos.

\section{Putas y militantes}

El accionar contra las mujeres en situación de prostitución por parte de Comando Moralizador Pío XII, no fue asunto individual ni producto de "excesos o errores" de algún agente policial aislado, sino que formó parte del armado del aparato represivo y del plan sistemático de exterminio perpetrado a partir de mediados de 1975, que se prolongó y profundizó durante la dictadura militar. ${ }^{40}$

Uno de los entrevistados, que había integrado en su juventud la agrupación Guardia Restauradora Nacionalista, señala que la persecución de judíos y las golpizas hacia mujeres en situación de prostitución callejera formaban parte de las prácticas llevadas a cabo por sujetos pertenecientes a esas asociaciones de la derecha vernácula. A ello se suman las intervenciones de José Martínez Blasco, Jefe de la Unidad Regional 2 de la policía de Mendoza, que intensificó la persecución hacia las mujeres en situación de prostitución bajo la idea de que era necesario llevar a cabo un "control de enfermedades venéreas" y cerrar los

40. RODRIGUEZ AGÜERO, Laura, "Ciclo de protestas...", Op. Cit. 
locales donde se ejerciera la prostitución. ${ }^{41}$ Por aquellos años se había presentado un proyecto para modificar el Código de Faltas utilizando el argumento de que era necesario controlar a las mujeres, e incluso obligarlas para que realizaran "tratamiento forzoso de la enfermedad". ${ }^{42}$ Bajo la idea de que la mayor parte estaban "infectadas", se realizaban operativos policiales durante los cuales se las detenía de manera legal, pues se había modificado a tal efecto el código de faltas. La posibilidad de detenerlas era ocasión para el abuso, la tortura y el asesinato. Los cuerpos mutilados y torturados eran arrojados en zona de montaña, junto con los de los primeros militantes asesinados por la represión paraestatal.

En mayo de 1975, a raíz del asesinato de dos mujeres en situación de prostitución por parte del Comando Moralizador Pío XII, el diario Los Andes puso en cuestión la información brindada por la policía, que se había encargado de vincular algunas de las muertes a conflictos internos del "hampa". Días después del asesinato de las dos mujeres, Los Andes publicó una crónica pormenorizada sobre catorce crímenes (algunos de personas no identificadas) cometidos desde fines del '74. E1 cronista comentaba que pocos días antes de su muerte: "la policía había arrestado a las víctimas

41. Claves, Mendoza, 21/9/1973. Martínez Blasco es considerado como responsable por delitos de Lesa Humanidad cometidos en Mendoza, debido a que detentaba por entonces un cargo jerárquico, del mismo modo que Julio Santuccione y otros ex agentes que pertenecieron a la policía de la provincia durante los años de la dictadura. La opinión sobre la responsabilidad de Martínez Blasco es de Ramón Abalo. En ABALO, Ramón, “Juicios II: el D2 será declarado organización criminal”. Disponible en: <http://www.mdzol.com/ opinion/331025-la-sentencia-el-d2-una-organizacioncriminal/> [Consulta: 8 de marzo de 2015]

42. Claves, Mendoza, Op. Cit.

60 y horas antes de su desaparición habían estado detenidas en la Brigada de Investigación de la Unidad Regional Primera". ${ }^{43}$

La particular asociación entre integrismo religioso y aparato represivo del Estado, la presencia de los dominicos y la construcción de la idea de enemigo interno unida a las nociones de "subversivo, terrorista, apátrida, por fuera de las leyes de la moral y la religión católica", hizo posible una particular política de represión sexual que generó por una parte la homologación entre militantes y prostitutas, y por la otra proporcionó una justificación ideológica a la aplicación de torturas y violaciones como formas de castigo legítimas.

En esa dirección, es iluminador el testimonio brindado en 2013 por el ex delegado bancario y miembro del Partido Revolucionario de los Trabajadores (PRT) Luis Ocaña, quien al igual que muchos ex presos/as políticos/as convivió con mujeres en situación de prostitución en los CCD:
Nos llevaban a los mismos lugares porque éramos la misma basura para ellos, que no merece vivir, que ensucia las calles...era lo mismo pintar una pared blanca que andar mostrando las gambas en la cuarta sección, les decían negras... como a nosotros... éramos víctimas del mismo odio de clase. ${ }^{44}$

Consideramos que no sólo de un asunto de "odio de clase" se trataba, sino de una profunda misoginia exasperada por la asociación entre fuerzas parapoliciales y derecha integrista. De ella deriva la vinculación entre lo que estos

43. Los Andes, Mendoza, 6/5/1975.

44. Entrevista realizada por Laura Rodriguez Agüero a Luis Ocaña, dirigente bancario, Mendoza, marzo de 2013. 
sectores suelen percibir como transgresiones al orden socio-sexual.

Autoras como Silvia Federici y Adrienne Rich proporcionan claves interpretativas que pueden iluminar el caso mendocino. ${ }^{45}$ La asociación entre derecha católica, grupos armados y el proceso de construcción de sujetos capaces de llevar a cabo "legítimamente" un plan sistemático de exterminio que incluyó la destrucción de la integridad sexual puede explicarse por una parte como efecto de la misoginia inculcada y normalizada a través de la formación religiosa, y por la otra a partir de un adoctrinamiento que proporcionaba a los agentes de la represión la seguridad de estar actuando en defensa de la moral, la patria, y el orden, que incluye normas específicas para las mujeres. El catolicismo de derecha, y los dominicos en particular, han sido pródigos en producciones simbólicas que asocian a las mujeres a un doble estándar: o bien putas o bien santas, o bien Marías, santificadas por la maternidad, o bien putas (como otrora brujas) merecedoras de los más brutales castigos. E1 desprecio hacia el cuerpo, la misoginia, el horror hacia la sexualidad se politizaron en una coyuntura que ponía a su disposición el aparato del Estado, además de grupos armados

45. Rich distingue "entre dos significados superpuestos de maternidad: la relación potencial de cualquier mujer con sus poderes reproductivos y con los/as hijos/as; y la institución, que apunta a asegurar que ese potencial -y todas las mujeres- permanezcan bajo el control masculino". RICH, Adrienne, Nacemos de mujer. La maternidad como experiencia e institución, Ediciones Cátedra, Valencia, 1996, p. 13. El carácter coercitivo de la institución resulta a tal punto normalizado que es invisible para quienes han sido socializados en sociedades patriarcales y heterosexistas. Las mujeres que escapan a la institución suelen ser objeto de brutales castigos. En este caso, la apropiación de los hijos de las guerrilleras formó parte del merecido escarmiento a quienes no merecían ser tenidas por una verdadera "madre". propios, como el Comando Pío XII, para llevar a la práctica la represión de las réprobas violándolas, despojándolas de sus hijos/as, torturándolas, golpeándolas, arrojando sus cuerpos al infierno de la desaparición. ${ }^{46} \mathrm{La}$ asociación entre la presencia de personajes asociados a los dominicos, la formación de bandas armadas formadas por integristas de derecha portadores de una concepción conservadora y patriarcal respecto del papel de lo que ellos denominan "la mujer" precipitó en una ofensiva contra las mujeres, cualesquiera hubiese sido la forma en que hubiesen transgredido los límites del estereotipo de buena mujer.

A la manera de los/las herejes y las brujas, militantes de ambos sexos y mujeres en situación de prostitución fueron sometidos a formas de castigo y persecución que recuerdan los métodos inquisitoriales utilizados durante los siglos XV y XVI. Los monjes Sprenger y Kramer justificaban de este modo la aplicación de tortura:

...la brujería es alta traición contra la Majestad de Dios. Y deben ser sometidos a tortura para hacerlos confesar. Cualquier persona, fuese cual fuere su rango o profesión, puede ser torturada ante una acusación de esa clase, y quien sea hallado

46. Spranger y Kramer eran dominicos. E1 Malleus Malleficarum, el manual que elaboraron, destila misoginia y odio al cuerpo y la sexualidad. El Malleus fue utilizado en Europa y América para la persecución de la brujería entre los siglos XV y XVIII, y los métodos recomendados, tortura y asesinato, se descargaron de manera sistemática contra mujeres, pues como ha señalado Silvia Federici existe un estrecho vínculo entre el control de los sujetos subalternos, la expropiación de los bienes comunes y el control de los cuerpos femeninos. Ver: FEDERICI, Silvia, Calibán y la bruja. Mujeres, cuerpo y acumulación originaria, Traficante de sueños, Madrid, 2004, p. 219 y ss. 
culpable, aunque confiese su delito, será puesto en el potro, y sufrirá todos los otros tormentos dispuestos por la ley, a fin de que sea castigado en forma proporcional a sus ofensas. ${ }^{47}$

Federici sostiene que el proceso de acumulación primitiva de capital asoció tres procesos: expropiación de los bienes comunes, exterminio de la población del Nuevo Mundo y esclavización de africanos, y cacería de brujas. Tomando su punto de vista consideramos que, en la coyuntura represiva desatada contra los y las militantes, que habían intentado no sólo transformar el orden capitalista sino las relaciones intergenéricas, la profunda articulación entre integrismo religioso y misoginia jugó un papel relevante en la legitimación de la revancha patriarcal. De manera no casual la persecución de militantes fue denominada por las fuerzas represivas "caza de brujas".

El odio misógino y la caracterización del enemigo político como "terroristas subversivos/ as apátridas" daba a estos personajes, que se construían a sí mismos como "guardianes de la patria y el honor" (que los varones tienen, pero encarna en los cuerpos de las mujeres), la autorización y legitimación para lanzarse sobre ellas/os: "putas" y militantes, varones y mujeres, con el objetivo de restaurar el orden abalanzándose sobre sus cuerpos, desgarrándolos en su integridad sexual. Como ha señalado Aucía, la violencia sexual no fue "abuso de poder", ni desviación individual, o exceso casual cometido por algún integrante del aparato represivo, sino "uso del poder conferido por el contexto político represivo

47. SPRENGER, Jacobus y Heinrich KRAMER, Malleus Maleficarum..., Op. Cit., p. 12.

62 y por el patriarcado". ${ }^{48}$ La finalidad era el "disciplinamiento de las mujeres y de los roles que deben cumplir socialmente". ${ }^{49}$ De allí el encarnizamiento contra las militantes, las mujeres en situación de prostitución y "los homosexuales", mencionados en el artículo 54 y 54 bis del Código de Faltas de la Provincia que pena la "Prostitución Escandalosa y (el) Homosexsualismo (SIC)". ${ }^{50}$

La asociación entre defensa del orden social y patriarcal, entre moralidad y una cierta versión de la religión, convocaba a los integrantes de bandas paraestatales y a la derecha armada, que atentaron contra personas vinculadas al ecumenismo y al Movimiento de Sacerdotes del Tercer Mundo que, por añadidura, estaban asociados a la experiencia local de crítica feminista del orden patriarcal y a la elaboración de las Pautas educativas. En octubre de 1973 el Comando de Operaciones Anticomunistas José Rucci realizó un atentado contra el filósofo Enrique Dussel. Dejaron panfletos en los que lo acusaban de "apátrida y de envenenar las conciencias de la juventud con la inmunda doctrina marxista". En septiembre de 1974 se produjo un atentado contra la imprenta Paulos, señalada como “...lugar donde el enemigo confeccionaba material ideológico

48. AUCÍA, Analía, "Género, violencia sexual y contextos represivos”, en AUCÍA, Analía, BARRERA, Florencia, BERTERAME, Celina, CHIAROTTI, Susana, PAOLINI, Alejandra y ZURUTUZA, Cristina, Grietas en el silencio..., Op. Cit., p. 65. En este trabajo la autora aborda la relación entre género y violencia sexual en los conflictos armados y en el marco del terrorismo de Estado argentino. Si bien no refiere al caso particular de Mendoza, hace un abordaje en el que brinda una serie de herramientas teóricas que nos permiten analizar el impacto diferencial que la violencia tuvo sobre tuvo sobre mujeres y varones en los CCD.

49. Ibídem.

50. Código de Faltas, art. 54-54 bis. 
que envenena las conciencias de la juventud". ${ }^{51}$ En una entrevista realizada en 2013, Concatti dice:

Hubo un grupo de laicos en aquellos años... armaron grupos para condenarnos. Muchos de ellos eran y todavía son profesores de la Universidad Nacional de Cuyo... pusieron una bomba en una imprenta que teníamos. No me cabe duda que fue este grupo de dominicos... No voy a dar nombres, porque tendría que probarlo. Pero alcanza con decir que fueron profesores de la ultraderecha mendocina. Por ejemplo, los hijos del profesor (Alberto) Falcionelli, condenado por nazi en Francia, andaban con armas encima. Les teníamos más miedo que a la policía. $^{52}$

En octubre de 1975 fue el turno de la casa de los ex curas tercermundistas Oscar Bracelis y Rolando Concatti. La colocación de esa bomba, como señala Concatti, estaba vinculada a los dominicos y a integrantes del nacionalismo de derecha. En noviembre de ese año un grupo armado irrumpió en la casa de Ezequiel Ander Egg y Norma Zamboni. Mauricio López, ligado también al movimiento de sacerdotes tercermundistas y figura clave en la ayuda a exiliados chilenos, fue secuestrado y desaparecido en enero de 1977.

\section{Tiempos de revancha: discursos y prácticas}

Una vez producido el golpe, la cruzada moral se agudizó. Los voceros de la dictadura consideraban que la intentona de transformar el mundo llevada a cabo durante los ‘60 y

51. Mendoza, Mendoza, 8/9/1974.

52. Los Andes, Mendoza, 30/11/1997. tempranos '70 no sólo incluía la pretensión de subvertir el sistema político-económico vigente, impulsado por la "infiltración marxista”, sino que tenía como blanco los valores de la moral hegemónica. Es decir que aquellos acusados de querer reemplazar la insignia celeste y blanca por "el inmundo trapo de la guerrilla" iban por la base de toda sociedad: la familia heterosexual, cristiana, legítimamente constituida. La cruzada de la dictadura era política y económica, pero también moral y religiosa.

Este papel "refundacional y de salvataje de la patria" de las FFAA se hace visible en los medios de comunicación. A lo largo de esos años Los Andes, el tradicional matutino mendocino, publicó una serie de notas que se concentran en la cuestión "moral", tópico central para la Junta Militar y al parecer para el diario. También tenía importantes espacios la Liga de Madres de Familia y la iglesia católica. A modo de ejemplo, en una nota del 31 de octubre de 1976, el obispo de San Juan repudiaba a una revista que había planteado la validez de parejas entre personas del mismo sexo. En la misma denunciaba:

La ola heredada de acción corrupta, contra el propósito vigente nacional, no se detiene sino que continúa confundiendo, corrompiendo y disociando al pueblo de la República... sabiendo que estas fuerzas que traen costumbres inmorales y degradantes del extranjero, atentan sustancialmente para alcanzar la patria que decididamente queremos quienes de verdad nos sentimos argentinos. ${ }^{53}$

En este fragmento, se observa la confluencia entre economía, política, moral y religión

53. Los Andes, Mendoza, 20/1/1977. 
mencionada al comienzo. Aquellos que habían atentado contra "la nación" también lo estaban haciendo contra las bases morales de la misma, contra uno de sus pilares: el matrimonio heterosexual.

No sólo los medios de comunicación planteaban la necesidad de refundación de la moral. Durante la gestión dictatorial, el Ministro de educación, Juan Llerena Amadeo, respondía ante la Cámara Argentina de Anunciantes, en una reunión del 10 de mayo de 1979: "Tenemos que oponer a la concepción materialista, marxista, los elementos que sirvan a nuestra juventud para evitar momentos tan afligentes como los que vivió la familia argentina en los últimos años". ${ }^{4}$ Tales elementos eran, en su concepción "las tradiciones de nuestra cultura y la concepción cristiana de la vida" ${ }^{55}$ que no sólo constituía la ley natural sin más, sino que era compartida por la mayoría de la población. La idea de una «refundación moral» está presente en el máximo nivel de decisión, en la educación y en la acción de las fuerzas militares y policiales, bendecidas por el episcopado argentino. ${ }^{56}$

En ese marco se entiende la persecución a las mujeres en situación de prostitución durante

54. LLERENA AMADEO, Juan, "Respuestas del Ministro de Cultura y Educación, doctor Juan Rafael Llerena Amadeo, a las preguntas de la Cámara Argentina de Anunciantes, formuladas en la reunión del 10 de mayo de 1979”, 1979, pp. 1-22; "Discurso de1 doctor Juan Rafael Llerena Amadeo", pronunciado el 22 de mayo de 1979 en el Consejo Nacional de Investigaciones Científicas y Técnicas (pp. 23-28) Buenos Aires, Ministerio de Educación de la Nación, p. 12.

\section{Ibídem.}

56. MIGNONE, Emilio Fermín, "Iglesia y dictadura. La experiencia argentina”, en Nueva Sociedad, Buenos Aires, 1986, № 82, pp. 121-128. la dictadura. Los operativos a partir de marzo de 1976, además de secuestrar "elementos subversivos", detenían y castigaban a estas mujeres "de mal vivir", tal como Los Andes registró en varias crónicas publicadas durante 1976 y $1977 .{ }^{57}$ Es decir que la equiparación entre "delincuentes subversivos" y "prostitutas" siguió vigente durante la dictadura.

Por otra parte, el trato que recibieron las personas apresadas por las fuerzas de seguridad incluyó la degradación, el hambreo, el hacinamiento, la desnudez forzada, la tortura y la violación, aplicada sistemáticamente sobre mujeres y varones. Con particular saña los carceleros violaron y torturaron a las mujeres más frecuentemente, pero también sometieron a violación a los varones, incluidos los heterosexuales, colocándolos en lugares vulnerabilizados. ${ }^{58}$ Asimismo y como contracara del discurso del elogio de la "familia" se apropiaron de niños y niñas, como fue el caso de Angela Urondo Raboy y Celina Manrique Terrera, además de los niños/as que nacieron en cautiverio de las embarazadas Pichona Moyano, Gladys Castro y Adriana Bonoldi. ${ }^{59}$

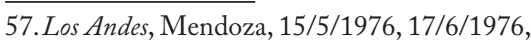
19/6/1976, 24/1/1977.

58. CIRIZA, Alejandra, “Sobre...”, Op. Cit., p. 12.

59. Ángela Urondo Raboy, luego del asesinato de su padre y desaparición de su madre, fue llevada a la Casa Cuna, donde fue encontrada por la familia materna. Celina Manrique Terrera fue apropiada ilegalmente luego de la desaparición de sus padres y recuperó su identidad en 2007. En agosto de 2015 Claudia Dominguez Castro, hija de los desaparecidos Gladys Castro y Walter Domínguez recuperó también la suya. Las organizaciones de Derechos Humanos de Mendoza continúan la búsqueda de los bebés, aparentemente nacidos en cautiverio, de las desaparecidas Moyano, Bonoldi, Roncelli y Correa Llano. 
Las violaciones y apropiaciones fueron cometidas por todos, a menudo con la bendición, si no con la condescendencia de la iglesia católica, y fueron parte del plan sistemático de exterminio de la llamada "subversión enemiga", considerados los y las militantes como menos que humanos, "terroristas apátridas".

La violencia sexual es una experiencia de violencia extrema cuyas víctimas habitualmente son mujeres, o varones ubicados en posiciones de subalternidad a los que se desea "feminizar", por así decir. Estos ataques a la integridad corporal, convertidos en norma para las mujeres en situación de prostitución y utilizados en contextos de prisión política y de tortura, lejos de ser excepcionales son habituales en sociedades patriarcales donde los cuerpos de las mujeres son significados como propiedad de algún varón, padre, patrón o marido, y como un medio para sus fines: placer, procreación, violencia, explotación, prostitución, acoso, abuso. Sólo un deseo parece poblar el imaginario social patriarcal, que es el dominante: el masculino. Sólo un sujeto activo, el varón, que no puede sino ser heterosexual. De allí que en la competencia entre machos poseedores los raptos, apropiaciones, esclavizaciones, violaciones masivas de "las mujeres del enemigo", hayan sido parte de la historia siempre repetida de la saga de "varones guerreros" y "mujeres reproductoras" o, lisa y llanamente, "putas". ${ }^{60}$

60. El asunto de la violación como un punto nodal en el control patriarcal sobre los cuerpos de las mujeres ha sido ampliamente tratado en el campo de los estudios feministas. Baste, sin embargo, señalar por su significación como textos de referencia obligada los escritos de Carole Pateman y Rita Segato. Para Paterman el contrato sexual es la contracara del contrato político. La violación de las mujeres por parte de los hermanos coligados, que asegura el sometimiento
$\mathrm{Si}$ de las violaciones cometidas contra militantes y mujeres en situación de prostitución, y de los secuestros de mujeres embarazadas y su destino hubo escaso registro, pues era preciso construir una imagen abominable del enemigo político, sin resquicios que hiciesen lugar a su humanidad, es notable la forma como el diario Los Andes relata el asesinato del poeta y militante montonero Paco Urondo, el secuestro de Alicia Raboy y el intento de apropiación de la niña Angela Urondo Raboy.

Según el diario Urondo fue "abatido" la noche del 17 de junio "como resultado de la actuación de las fuerzas del orden”. Su mujer herida habría huido y dejado abandonado en el auto "un niño" (sic) de un año. ${ }^{61}$ El título de la nota era "Abatieron en Mendoza a un delincuente subversivo. Usó como escudo a un niño". La crónica ponía especial acento, una vez más, en la falta de humanidad de los "subversivos":

Este proceder, de utilizar niños como escudo para llevar a cabo sus asesinatos, exponiéndolos a ser heridos o muertos durante la acción y abandonándolos a su suerte ante el menor fracaso, habla claramente de la poca moral y desviados

mujeril y es marca de su derrota politica, habilita la escisión entre derecho civil y derecho político, entre el carácter corporizado de la vida en la sociedad y la familia y el carácter abstracto de la vida política, habitada por individuos sin determinaciones corporales que, sin embargo, son varones. Ver: PATEMAN, Carole, El contrato sexual, Barcelona, Anthropos, 1995. Por su parte Rita Segato afirma, en su conocido estudio sobre la violencia que la violación es una suerte de reparación del orden patriarcal dañado. SEGATO, Rita, Las estructuras elementales de la violencia, Universidad Nacional de Quilmes, Bernal, 2003.

61. Los Andes, Mendoza, 19/6/1976. 
sentimientos que animan a estos delincuentes subversivos". ${ }^{62}$

En el discurso de los militares y sus aliados los enemigos, constantemente identificados como "delincuentes, terroristas, subversivos, apátridas", encarnaban la puesta en cuestión de todos los valores de la moral, asimilados sin más a los de la religión católica. Las mujeres, según esta versión, eran particularmente crueles, capaces de abandonar a sus hijos/as, exponerlos/as al peligro y tomar las armas.

Como bien ha dicho la investigadora Marta Vasallo, las guerrilleras eran "mujer [es] que se salía[n] de su rol hasta el punto no sólo de aspirar a alguna forma de poder público sino de elegir además la vía de las armas, terreno exclusivo de la agresividad y heroísmo varonil". ${ }^{63}$ Alicia Raboy, como tantas otras, fue demonizada a través de la crónica periodística, que la acusaba de haber usado de "escudo humano" a su hijita que la acompañaba en el auto y de haberla abandonado, cuando en realidad la niña le había sido arrebatada y ella había sido secuestrada y desaparecida.

El elogio de la moral y la familia "occidental y cristiana" parecen haber justificado el castigo hacia todos/as aquellos/as que habían atentado contra todo cuanto los represores y sus cómplices consideraban "sacrosanto".

62. Ibídem.

63. VASALLO, Marta, "Militancia y transgresión" en ANDÚJAR, Andrea, D’ANTONIO, Débora, GIL LOZANO, Fernanda, GRAMMÁTICO Karin y ROSA, María Laura (compiladoras) De minifaldas, militancias y revoluciones. Exploraciones sobre los 70 en la Argentina, Luxemburg, Buenos Aires, 2009, p. 29.

66

\section{Algunas consideraciones finales}

Luego del análisis realizado pudimos observar de qué manera, a escala local, se manifestó la mencionada «restauración moral». Tanto las experiencias de los Seminarios educativos como las actividades realizadas alrededor del Centro de Investigaciones de la Mujer, que fueron parte de ese proceso, fueron percibidas como "peligrosas" por parte de la derecha local, y quienes de ellas participaron fueron víctimas de represalias por parte de organizaciones paraestatales que nucleaban a las fuerzas de seguridad y a grupos nacionalista de derecha, grupos que también actuaron sobre sus opositores políticos y procedieron a la cacería de mujeres en situación de prostitución en connivencia con el aparato represivo del Estado.

Estos grupos estaban ligados a los dominicos, cuyo papel fue central para la elaboración de justificaciones ideológicas del accionar represivo, del uso de la tortura como herramienta de disciplinamiento $y$ moralización, y para la construcción de una idea de enemigo que establecía continuidad entre militantes y mujeres en situación de prostitución. En el análisis realizado también pudimos ver cómo la persecución a mujeres en situación de prostitución, lejos de haber sido un hecho aislado producto de "excesos" de algún agente policial, fue parte de los primeros pasos del terror en Mendoza. A su vez, abordar estos procesos en un período que abarca siete años, nos permitió analizar algunas continuidades del proceso represivo antes y después del golpe, tales como la represión a prostitutas, el carácter moral del discurso militar, y la continuidad en el carácter sexuado de la represión que se 
manifestó en la homologación entre prostitutas y militantes por parte de los perpetradores del terror.

Tras el golpe de Estado, los militares y sus aliados desplegaron una cerrada retórica respecto de la moral, la institución familiar, el lugar de las mujeres y la sexualidad. Paladines en la defensa de la patria y el honor, reivindicaban para la Argentina la "tradición occidental y cristiana" a la vez que aplicaban sistemáticamente secuestros, torturas, violaciones cruentas y apropiaciones ¿Cómo compatibilizar el elogio de la moral con la violación como arma de destrucción de la integridad sexual del otro/la otra? ¿Cómo ligar el elogio de la familia con el asesinato de mujeres embarazadas, el secuestro y la privación de identidad practicada con niños $\mathrm{y}$ niñas pequeños? $\mathrm{Y}$ sin embargo, para los perpetradores del terrorismo de Estado y para la lógica patriarcal y misógina del catolicismo integrista, parecen haber sido compatibles: mujeres en situación de prostitución y mujeres militantes son violables, pues nada hay en ellas de honestidad y honor.

La cacería de seres humanos degradados, de la misma manera que los herejes y las brujas en los albores del capitalismo, se repitió en la Argentina bajo la bendición y los argumentos elaborados por los mismos que en siglo XV habían escrito minuciosos manuales para obtener confesiones y justificar torturas. La construcción de la bruja, del "hereje", del "delincuente subversivo", de las "mujeres de mala vida" justifica de antemano la muerte. $\mathrm{La}$ "revancha clasista" tuvo su complemento necesario en la "revancha patriarcal" sellando una vez más la alianza entre capitalismo y patriarcado. 


\section{Bibliografía}

ABALO, Ramón, “Juicios II: el D2 será declarado organización criminal”. Disponible en: <http://www. $\mathrm{mdzol.com/opinion/331025-la-sentencia-el-d2-una-organizacion-criminal>} \mathrm{[Consulta:} 8$ de marzo de 2015].

ANDER EGG, Ezequiel, ZAMBONI, Norma, GISSI, Jorge, DUSSEL, Enrique, Opresión y marginalidad de la mujer en el orden social machista, Humanitas, Buenos Aires, 1972.

AUCÍA, Analía, BARRERA, Florencia, BERTERAME, Celina, CHIAROTTI, Susana, PAOLINI, Alejandra y ZURUTUZA, Cristina, Grietas del silencio. Una investigación sobre la violencia sexual en el marco del terrorismo de Estado, CLADEM, Insgenar, Buenos Aires, 2011.

BACCI, Claudia, CAPURRO, María, OBERTI, Alejandra y SKURA, Susana, "Entre lo público y lo privado: los testimonios sobre la violencia contra las mujeres en el terrorismo de Estado en Argentina", en Clepsidra, Revista Interdisciplinaria de Estudios sobre la Memoria, Revista del Núcleo de Estudios sobre Memoria (IDES), Buenos Aires, 2014, Año 1, No 1, pp. 122-139.

BALARDINI, Lorena, OBERLIN, Ana y Sobredo, Laura, "Violencia de género y abusos sexuales en centros clandestinos de detención. Un aporte a la comprensión de la experiencia Argentina”, en CELS, Hacer justicia. Nuevos debates sobre el juzgamiento de crímenes de lesa humanidad en la Argentina, Siglo XXI, Buenos Aires, 2011.

BASUALDO, Victoria, "Complicidad patronal-miliar en la última dictadura militar. Los casos Acindar, Astarsa, Dálmine, Siderca, Ford, Ledesma y Mercedes Benz”, en Suplemento especial Revista Engranajes, Buenos Aires, 2006, No 5, FETIA.

CIRIZA, Alejandra, "Sobre las violaciones cometidas en los centros clandestinos de detención como delitos de lesa humanidad", en Sin Permiso. Disponible en: <http://www.sinpermiso.info/textos/index. php?id=3807>, [Consulta: 7 de setiembre de 2014]

D’ANTONIO, Débora, "Los presos políticos del penal de Rawson: un tratamiento para la desubjetivación. Argentina (1970 1980), en Anos 90, Dossiê Ditaduras de Segurança Nacional no Cone Sul, Porto Alegre, 2012, V. XIX, No 35, pp. 141-168.

FARES, Celina, "Tradición y reacción en el Sesquicentenario. La escuela sevillana mendocina”, en Prismas, Bernal, 2011, V.XV, No 1, pp. 87-104.

FEDERICI, Silvia, Calibán y la bruja. Mujeres, cuerpo y acumulación originaria, Traficante de sueños, Madrid, 2004.

LVOVICH, Daniel, El nacionalismo de derecha, desde sus orígenes a Tacuara, Capital Intelectual, Buenos Aires, 2006.

MIGNONE, Emilio Fermín, "Iglesia y dictadura. La experiencia argentina”, en Nueva Sociedad, Buenos Aires, 1986, № 82, pp. 121-128. 
PATEMAN, Carole, El contrato sexual, Barcelona, Anthropos, 1995.

RANALETTI, Mario, "La guerra de Argelia y la Argentina. Influencia e inmigración francesa desde 1945”, en Anuario de Estudios Americanos, Sevilla (España), 2005, V. LXII, No 2 pp. 285-303.

RANALETTI Mario y PONTORIERO, Esteban, "La normativa en materia de defensa y seguridad y la criminalización de las disidencias (1955-1976)", ponencia presentada en VJornadas de Trabajo sobre Historia Reciente, Universidad Nacional de General Sarmiento, Los Polvorines, 2010.

RICH, Adrienne Nacemos de mujer. La maternidad como experiencia e institución, Ediciones Cátedra, Valencia, 1996.

RODRIGUEZ AGÜERO, Laura, "Ciclo de protestas, experiencias organizativas y represión paraestatal. Mendoza, 1972-1976”, Tesis Doctoral, Universidad Nacional de La Plata, 2013.

SEGATO, Rita, Las estructuras elementales de la violencia, Universidad Nacional de Quilmes, Bernal, 2003.

SPRENGER, Jacobus y KRAMER, Heinrich, Malleus Maleficarum (El martillo de las brujas), Reeditar, España, 2006.

VASALLO, Marta, "Militancia y transgresión” en ANDÚJAR, Andrea, D’ANTONIO, Débora, GIL LOZANO, Fernanda, GRAMMÁTICO Karin y ROSA, María Laura (compiladoras) De minifaldas, militancias y revoluciones. Exploraciones sobre los 70 en la Argentina, Luxemburg, Buenos Aires, 2009. 